\title{
The Model of Adaptive Learning Objects for virtual environments instanced by the competencies
}

\author{
Carlos Guevara ${ }^{1 *}$, Jose Aguilar ${ }^{2,3}$, Alexandra González-Eras ${ }^{3}$ \\ ${ }^{1}$ Centro de Investigaciones en Informática y Tecnologías de la Computación - CITEC, Universidad Nacional Experimental de Guayana, \\ 8050, Ciudad Guayana, Venezuela.
}

${ }^{2}$ Centro de Estudios en Microelectrónica y Sistemas Distribuidos - Universidad de Los Andes, 5101, Mérida, Venezuela. Prometeo Researcher - Universidad Técnica Particular de Loja, Escuela Politécnica Nacional, Ecuador

${ }^{3}$ Departamento de Ciencias de la Computación y Electrónica, Universidad Técnica Particular de Loja, 1101608, Loja Ecuador

\begin{tabular}{l} 
A R T I C L E I N F O \\
\hline Article history: \\
Received: 25 March, 2017 \\
Accepted: 04 May, 2017 \\
Online: 17 May, 2017 \\
\hline Keywords: \\
Adaptive Learning Object \\
Virtual Environment \\
Virtual Education Competencies \\
\hline
\end{tabular}

\begin{abstract}
A B S T R A C T
This article presents the instantiation of the Model of Adaptation of Learning Objects (MALO) developed in previous works, using the competencies to be developed in a given educational context. MALO has been developed for virtual environments based on an extension of the LOM standard. The model specifies modularly and independently two categories of rules, of adaptation and conversion, giving it versatility and flexibility to perform different types of adaptation to the learning objects, incorporating or removing rules in each category. In this work, we instance these rules of MALO using the competencies considered in a given educational context.
\end{abstract}

\section{Introduction}

The Information and Communication Technologies (ICT) have been introduced in the field of the education, in order to extend and improve the teaching-learning processes. In these environments, the use of learning objects (LO) is becoming more relevant every day to facilitate the teaching-learning process. LO are understood as any digital resource that can be used to support learning [1].

On the other hand, the interest of incorporating adaptive capacities, both to learning objects and virtual learning environments, has increased in recent years. However, there is no uniformity about what should be considered as an Adaptive Learning Object (ALO) [2-12]. In general, there are several works that are being developed on ALO and its application in virtual education. Most of these works are mainly focused on the adaptation of LO to the virtual teaching-learning process considering several aspects, among which we can mention: the learning style of the students; the course offered; the types and means of storages; and the learning trajectories [29], in order to

\footnotetext{
*Corresponding Author: Carlos Guevara, Centro de Investigaciones en Informática y Tecnologías de la Computación - CITEC, Universidad Nacional Experimental de Guayana, Venezuela | Email: carlos.guevaraf@gmail.com
}

create a favorable and an optimal environment for the successful development of virtual education.

Another aspect to consider is the adaptability of the LO's as support to the formation of competences, assuming that a student has previous competences that will be strengthened during the learning process until reaching an objective competence [26]. In this sense, within the learning trajectories are established states of skills and knowledge to be reached, which determine the level of customization of the LOs in terms of its granularity (knowledge) and skills required in them, for the acquisition of these competence goals [25-29]. This is the approach that we are interested in this work.

Due to the boom of virtual education and the application of emerging paradigms in the teaching-learning processes, combined with the weaknesses found in the various papers reviewed about ALO, we have presented in a previous work a Model of Adaptation of Learning Object (MALO) reconfigurable [2], based on the Learning Object Metadata (LOM) standard [3]. In this paper, we test the capability of reconfiguration of MALO, where its adaptation is guided by the competencies to be reached in a given course, that means, determining the level of adaptation of the LOs using MALO, according to the competencies to be 


\section{Guevara et al. / Advances in Science, Technology and Engineering Systems Journal Vol. 2, No. 3, 345-355 (2017)}

reached. In this case, the rules are redefined based on an autonomous adaptation of the LO.

This article is organized as follows, the next section presents some theoretical aspects, and then we present in detail to MALO. The next section presents the example of adaptation of MALO using competencies, and finally, we compare MALO with previous work.

\section{State of the art}

In [4] is proposed an ALO model composed of four components, a knowledge domain model, a user domain model, a context model, and finally a session model. The fourth component is responsible for establishing relationships between the other three components, through navigation rules, content presentation rules, and rules of personalization of the information presented to the user. In that work, the rules of adaptation are specified to each ALO, which makes its implementation difficult. In addition, these are limited to navigation patterns within a LO. Finally, the proposal only presents rule statements, without any implementation. [5] presents an ALO model for t-learning, a term adopted to refer to learning through interactive digital television. The idea that they pursue is to offer LO with different behaviors, depending on the characteristics of the users. To do this, they use an XML file that contains a template with rules of adaptation of parameters, which indicate to the educational object what behavior or appearance to adopt according to the student's preferences. In this work, they do not incorporate autonomous changes in the learning process.

In order to construct Adaptive Learning Systems, in [6] is proposed a model considering the granularity properties of the LO. Its proposal is based on the adaptation of the LO, by adding four levels of functionality: courses, documents, fragments of the document and multimedia pieces. The fragments are made up of multimedia pieces related to some instructional objective and a semantic description, which allows them to assemble a new learning object from the existing ones. The architecture presented in [6] is composed of 3 main components, a Domain Model formed by the concepts that the learner must learn; a Learner Model, which represents the learner's information; and an Adaptation Model, which is responsible for the adaptation of the contents that are presented to the learner, and the way the fragments are assembled. In this model, the authors use a modular and structured treatment of the adaptation process, however, they do not consider the technological limitations, and nor do they describe the rules to be used to adapt to LO.

The work developed by [7], establishes a relationship between adaptation needs and learning materials. It considers that the needs of adaptation are influenced by the user, according to their cognitive and learning styles; the context, through the location and tasks that the user performs; and the learning material, with its own characteristics. They determine 13 adaptation criteria, which can be useful for classifying content and adapting LO. However, they do not present a model guiding how to incorporate these adaptation criteria into a LO. In [29] propose an adaptive framework of LOs, assessment items, and competences. In specific, the competencies are defined by the prerequisite.

\section{Theoretical Aspects}

\subsection{Learning Object}

There are several definitions of LO, some of them are: "any digital resource that can be used to support learning" [1], "any entity, digital or non-digital, that maybe be used for learning, education or training" [8], "an element with recyclable digital multimedia content documents, which has a purpose and use in instruction and learning" [9].

According to the definitions cited, [8] considers LO in a rather broad sense, by including in it any resource, both digital and nondigital, that can be used for learning, education or entertainment. On the other hand, [1] delimits it only to digital resources, so this definition is more oriented to digital technology. For its part, [9] makes explicit the use of digital documents with multimedia contents in the learning process.

This shows that there is no consensus on the definition of LO. For the purpose of this research, the interest is focused on LO used in virtual environments, what can be called Virtual Learning Objects. Therefore, $\mathrm{LO}$ will be considered a reusable multimedia digital resource, which can be used in learning, and employ metadata for description. This highlights two important aspects in LO: it is a digital resource with multimedia features for educational purposes, and the metadata is used for its description to facilitate its discovery and reuse.

In general, a LO has a set of attributes, such as reusability, portability, modularity, granularity, accessibility, flexibility, interoperability and durability. In specific, the granularity is an important property, because it facilitates its scalability and adaptation, and it simplifies the coupling or combination of different LO to form a new one. Some authors consider granularity from the point of view of the number of concepts or ideas contained in the LO $[1,18]$. Others, such as the LOM standard of IEEE, consider it as the amount of media or formats that are combined in a LO [6]. For purposes of this work, granularity is assumed from three approaches:

- Concepts or ideas combine in a learning object, which provide the semantic density of the LO

- Media or formats that are combined in a LO. They determine how the content is presented in LO.

- Parts or elements in which the content of the LO is organized. It is like the contents table, where, for example, the document parts, the book chapters, or the course subjects, are indicated.

\subsection{Standards for production of Learning Objects}

The standards for LO are grouped into metadata standards and standards for the creation of educational platforms. The first seeks to describe and provide $\mathrm{LO}$ properties and information to facilitate and optimize their manipulation; while the second helps to define virtual environments that integrate a set of tools that provide support to the online teaching-learning process. Among the most widely used metadata standards are the Dublin Core [10] and the IEEE LOM, while SCORM and IMS are used for the creation of educational platforms.

In our work, we use the LOM standard, which is a data model proposed by the IEEE, through the Learning Technology Standards Committee (LTSC), to describe a learning resource and its components. The purpose of the standard is to facilitate the 


\section{Guevara et al. / Advances in Science, Technology and Engineering Systems Journal Vol. 2, No. 3, $345-355$ (2017)}

search, evaluation, acquisition and use of educational objects, as well as, to promote their exchange, reusability and share use. It consists of 80 descriptors, grouped into nine categories [3]. Each descriptor defines a specific aspect to be considered to describe a LO. Table 1 shows the categories defined in the LOM Standard.

Table 1. LOM Standard Summary [3].

\begin{tabular}{|l|l|l|}
\hline $\mathbf{N}^{\mathbf{N}}$ & \multicolumn{1}{|c|}{ Category } & \multicolumn{1}{|c|}{ Description } \\
\hline 1 & General & $\begin{array}{l}\text { This category groups the general information that } \\
\text { describes the learning object as a whole }\end{array}$ \\
\hline 2 & Life Cycle & $\begin{array}{l}\text { This category describes the history and current state } \\
\text { of the learning object and those entities that have } \\
\text { affected this learning object during its evolution. }\end{array}$ \\
\hline 3 & $\begin{array}{l}\text { Meta- } \\
\text { Metadata }\end{array}$ & $\begin{array}{l}\text { This category describes the metadata record itself } \\
\text { (rather than the learning object that this record } \\
\text { describes) }\end{array}$ \\
\hline 4 & Technical & $\begin{array}{l}\text { This category describes the technical requirements } \\
\text { and characteristics of this learning object. }\end{array}$ \\
\hline 5 & Educational & $\begin{array}{l}\text { This category describes the key educational or } \\
\text { pedagogic characteristics of this learning object. }\end{array}$ \\
\hline 7 & Rights & $\begin{array}{l}\text { This category describes the intellectual property } \\
\text { rights and conditions of use for the learning object }\end{array}$ \\
\hline 8 & Relation & $\begin{array}{l}\text { This category defines the relationship between this } \\
\text { learning object and other learning objects, if any. }\end{array}$ \\
\hline 9 & $\begin{array}{l}\text { This category provides comments on the } \\
\text { educational use of this learning object, and } \\
\text { information on when and by whom the comments } \\
\text { were created }\end{array}$ \\
\hline
\end{tabular}

The LOM standard is considered as an extension of the Dublin Core standard, with additional elements for the description of educational resource properties. For this reason, to represent the LO metadata, in this work we decided to use the standard LOM

\subsection{Competencies}

The definition of competence is derived from the Latin word "competere", which means "to be adequate", that implies "the combination of skills, attitudes and knowledge necessary to carry out a task effectively" [11]. In this way, the elements of the competence are the skills and knowledge. The knowledge comprises the set of topics and themes that are part of a profession and that the students need to develop, while the skill represents the abilities to use the knowledge in the development of an activity [12]. Thus, the competence defines the person's ability to perform a task [26], as a result of the relations between a specific knowledge, and a know-how [13].

In the learning contexts, the definition of competence refers to the set of skills and knowledge to solve specific problems [26], which relate the previous competences that the student has and the objective competence, i.e. the problem to be solved [29]. Depending on the objective competence, can be set the knowledge and skill levels required, and with the learner's current knowledge and skill state, can be determined the learning trajectory. Based on this learning trajectory, personalized learning paths and adequate LOs can be defined.
The Figure 1 shows the process of constructing of the objective competence: "to establish the difference between a vegetarian dish and others" proposed in Table 11. According to the Figure 1, can be set the learning trajectory knowledge and skills required to fulfill the objective competence, taking as a starting point the previous competence that the student possesses and defining evaluation moments in the learning trajectory.

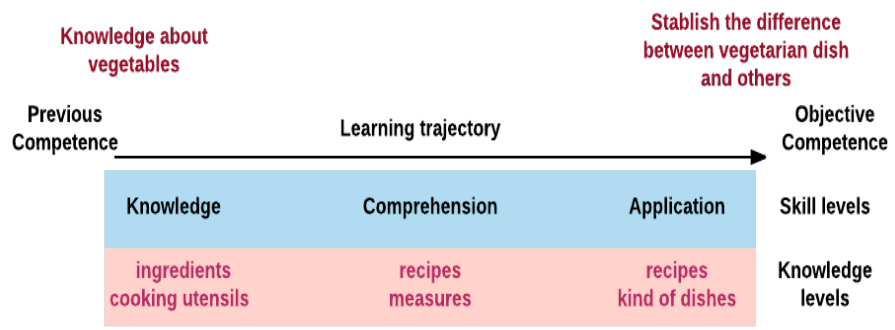

Figure 1. Objective competence construction in a learning trajectory

\subsection{MASINA Methodology}

MASINA (MultiAgent Systems for INtegrated Automation) is a methodology developed for the modeling of systems of engineering oriented to agents. It uses the Unified Modeling Language (UML), and the Object Systems Development Technique (OSDT), which is a tool for the formal specification of object-oriented models [23, 24]. It covers the phases of conceptualization, analysis, design, coding and testing, and integration. Now, we describe only the phase and model used in our work, for more detail see [23, 24]

- Conceptualization: allows to identify the actors of the system and their use cases. In this phase basically the extraction and acquisition of the knowledge is realized to obtain a first description of the system. The main product of this phase is a conceptualization document, which contains the analysis of the problem, and the use cases with the description of the components of the system. The use case defines the list of actions of each a role in our system, to achieve a goal.

- Analysis: it allows to describe the system, its objectives and tasks, capabilities, interactions, etc. The main product of this phase is a set of models like the task model, that describe each component of the system at the level of its procedure, condition of utilization, etc. of the different component, to be considered.

In our work, we use these two first phases to design MALO, and particularly, the task and user case models of MASINA.

\section{Model of Adaptation of Learning Object (MALO)}

For the formal description of the model, we used the MASINA methodology proposed in [23-24], and UML diagrams. However, before the presentation of MALO, it is necessary to define an ALO.

\subsection{Definition of $A L O$}

An ALO is considered a reusable multimedia digital resource that can be used in a learning process, which contains metadata for its description, and is able to adapt to the context. The ALO concept is presented in Figure 2, through a use case diagram, and in the Figure 3 its activity diagram. 


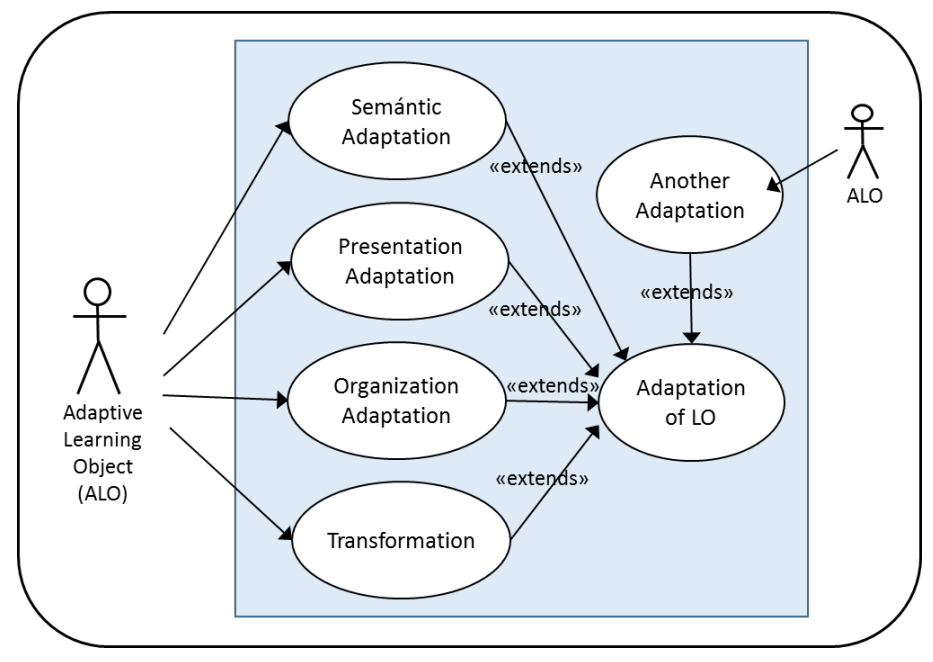

Figure 2. Use Case Diagram of an ALO

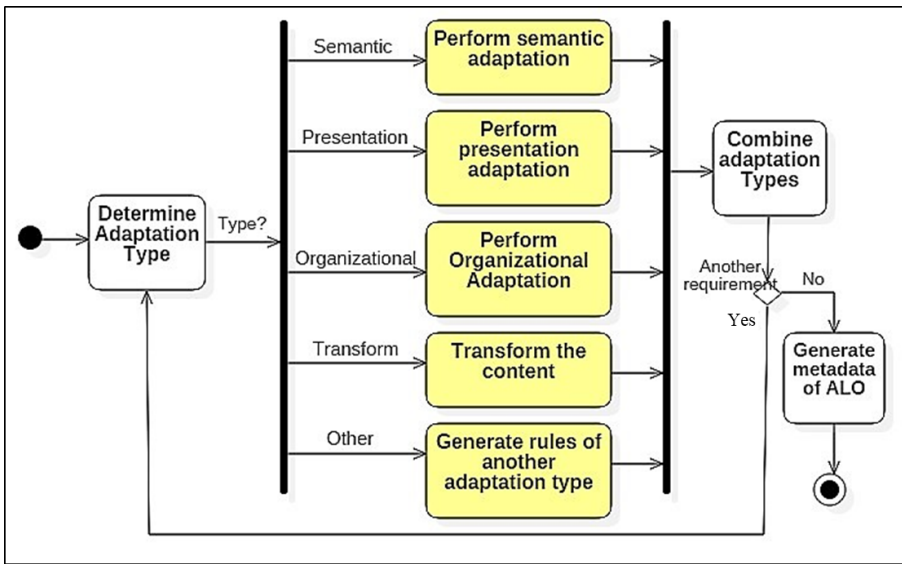

Figure 3. Activity Diagram of an ALO

As can be seen in the ALO activity diagram, its adaptation is a complex, recursive and dynamic process, where several types of adaptation can occur simultaneously, in addition, it has the flexibility to include other types of adaptation in the future. The ALO use case description is presented in Table 2, and the description of the types of adaptation is given in the following subsections. In the use case, we can see the adaptation procedure of the ALO, which can fail if there are not the services for the adaptation process. Also, the precondition conditions are very clear, we need to define the adaptation requirements that can be defined in our case, by the competencies to be reached.

Table 2. Use Case Description of an ALO

\begin{tabular}{|l|l|}
\hline Use Case & Adaptive Learning Object \\
\hline Description & $\begin{array}{l}\text { It processes the requirements of adaptation of a } \\
\text { LO. }\end{array}$ \\
\hline Precondition & Adaptation requirements \\
\hline Actors & Adaptive Learning Object \\
\hline Procedure & $\begin{array}{l}\text { Begin } \\
\text { Determine types of adaptation required } \\
\text { If type = semantic then } \\
\text { Adapt semantically the LO } \\
\text { If type = organization then } \\
\text { Adapt organizationally the LO } \\
\text { If type = presentation then } \\
\text { Adapt the presentation of the LO }\end{array}$ \\
\hline
\end{tabular}

$\underline{\text { www.astesj.com }}$

\begin{tabular}{|l|l|}
\hline \multirow{1}{*}{} & $\begin{array}{l}\text { If type }=\text { transformation then } \\
\text { Transform the LO content } \\
\text { If type }=\text { other then } \\
\text { Generate the rules of another type of } \\
\text { adaptation of the ALO } \\
\text { Combine the types of ALO adaptation until to } \\
\text { reach the requirements } \\
\text { Generate Matadata of ALO } \\
\text { End }\end{array}$ \\
\hline Fail condition & $\begin{array}{l}\text { Not having the necessary services to process the } \\
\text { LO adaptation requirements }\end{array}$ \\
\hline $\begin{array}{l}\text { Success } \\
\text { condition }\end{array}$ & Build a LO adapted to the required specifications \\
\hline
\end{tabular}

\subsection{MALO Description}

MALO has been defined in detail in [21]. In this section, we present a resume of MALO. Figure 4 presents MALO, which is composed of 4 elements:

- LO: are the Learning Objects to adapt, according to the information obtained from the context.

- Units: they are small blocks, such as concepts, media or pieces, that compose a LO. The number of units present in the LO, define their granularity and complexity.

- Rules: two categories of rules are defined, Adaptation and Conversion, which specify, respectively, the structural or contextual adjustments made to a LO.

- Adaptation Metadata: it is an extension of the LOM standard, which describes the data and processes required to facilitate the process of adaptation of the LO.

A LO can be decomposed into smaller units by using rules of conversion, forming a set with simpler LO, increasing its granularity; or conversely, starting from a set of LO, a more complex LO can be formed with less granularity. With the use of the rules of adaptation, the LO is adapted to certain specifications of the context in which it is immersed.

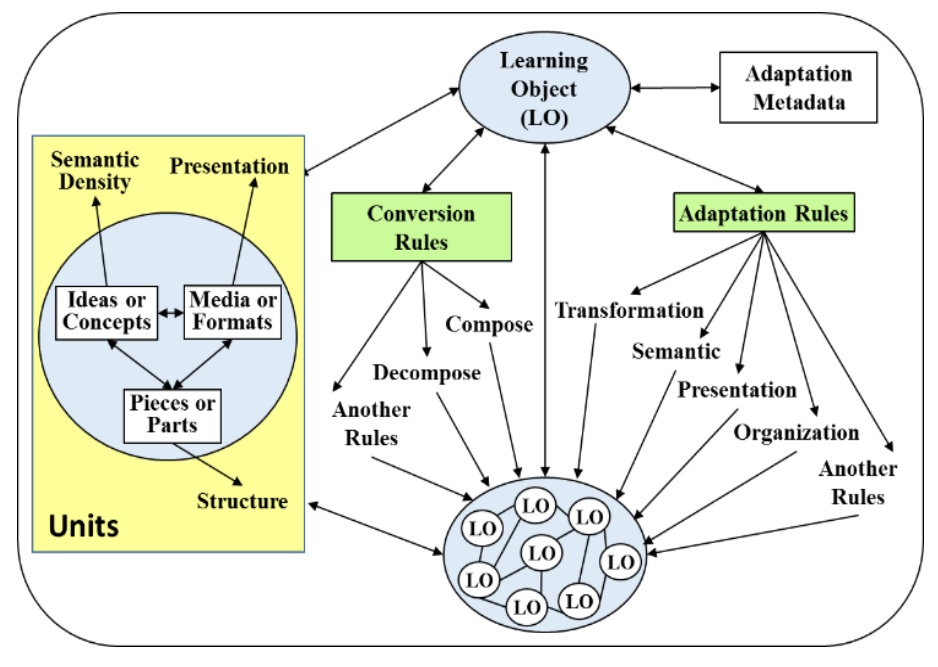

Figure 4. MALO

The result of applying the adaptation and conversion rules to an ALO is a Learning Object with a new semantic, or a new presentation format of the content, or a new organization, among 
other things; based on the parameterization of an existing one, or the combination of several of them.

\subsubsection{Conversion Rules}

The conversion rules indicate that structural adaptations of a LO. In this article, two conversion rules are defined, however, MALO has the flexibility to allow the incorporation of new rules. The basic conversion rules are:

- Composition: based on the principle of reusability, allows to build new LO from other LOs of less granularity. The description of the composition rule is presented in Table 3, which has 5 rules.

- Decomposition: allows to decompose a LO into several LOs of less granularity, or to extract units included in a digital content. The description of the decomposition rule is presented in Table 4, which has 7 rules.

Table 3. Task Model of the Composition Rule

\begin{tabular}{|c|c|}
\hline \multicolumn{2}{|r|}{ COMPOSITION OF A LEARNING OBJECT } \\
\hline Name & Composition \\
\hline Objective & Compose a LO from other LOs. \\
\hline Description & $\begin{array}{l}\text { Composes the content of a LO by total or partial } \\
\text { aggregation of units (concepts, pieces, media) } \\
\text { contained in other LOs }\end{array}$ \\
\hline Precondition & Units required \\
\hline Subtask & $\begin{array}{l}\text { - Define the LO organization to be built } \\
\text { - Add concepts or ideas } \\
\text { - Add pieces or parts of the structure of a LO } \\
\text { - Add media or formats to the contents of a LO } \\
\text { - Generate metadata of the new LO }\end{array}$ \\
\hline Product & Adaptive Learning Object \\
\hline
\end{tabular}

Ingredients-Compose Learning Object

Composition $\quad$ Indicates the type of composition to be made.

\begin{tabular}{l|l} 
Type & Values $=$ semantics, organization, format, mixed \\
\hline
\end{tabular}

\begin{tabular}{l|l} 
Concepts List & Concepts or ideas contained in a LO \\
\hline
\end{tabular}

\begin{tabular}{|l|l|}
\hline Pieces List & Different elements or part in which the LO is
\end{tabular} organized, similar to a table of contents. For example, document parts, book chapters, course topics, workshop content and activities.

\begin{tabular}{l|l} 
Formats List & Different media or formats that are combined in a LO.
\end{tabular}

Values $=$ Text, Audio, Video, Interactive Animation, Simulator, Image, Table or Chart, Diagram.

Table 4. Task Model of the Decomposition Rule

\begin{tabular}{|l|l|}
\hline \multicolumn{2}{|c|}{ DECOMPOSITION OF A LEARNING OBJECT } \\
\hline Name & Decompose \\
\hline Object & Decompose a LO in order to increase its granularity \\
\hline Description & $\begin{array}{l}\text { Disaggregate the content of a LO by units (ideas or } \\
\text { concept, parts or parts, formats or media) }\end{array}$ \\
\hline Precondition & Requirement of concept, piece or format \\
\hline Subtask & $\begin{array}{l}\text { - Search for concepts / ideas contained in a LO } \\
\text { - Extract concepts or ideas from a LO } \\
\text { - Extract organization of a LO } \\
\text { - Remove parts of the structure of a LO } \\
\text { - Search for formats / media embedded in a LO } \\
\text { - Extract media or formats contained in a LO } \\
\text { - Generate metadata of the new LOs }\end{array}$ \\
\hline Product & Learning objects with greater granularity \\
\hline
\end{tabular}

\begin{tabular}{|l|l|}
\hline \multicolumn{2}{|l|}{ Ingredients- Decompose Learning Object } \\
\hline $\begin{array}{l}\text { Decomposition } \\
\text { type }\end{array}$ & $\begin{array}{l}\text { - Indicates the type of decomposition required } \\
\text { Values = semantics, structure, format, mixed }\end{array}$ \\
\hline Concepts List & - Concepts or ideas contained in a LO \\
\hline Pieces List & $\begin{array}{l}\text { - Different elements or part in which the LO is } \\
\text { organized, similar to a table of contents. For } \\
\text { example, document parts, book chapters, course } \\
\text { topics, workshop content and activities. }\end{array}$ \\
\hline Formats List & $\begin{array}{l}\text { Different media or formats that are combined in a } \\
\text { LO. } \\
\text { Values = Text, Audio, Video, Interactive } \\
\text { Animation, Simulator, Image, Table or Chart, } \\
\text { Diagram. }\end{array}$ \\
\hline
\end{tabular}

\subsubsection{Adaptation Rules}

The rules of adaptation define the types of adjustments to be applied to the LOs to contextualize it. In MALO, four types of rules are initially defined:

- Semantics: they allow to define new semantics in a LO, incorporating other ideas, conceptualizations or lexicons, according to its content.

- Presentation: allows to adapt the presentation of the LO, adjusting its formats to the preferences, limitations and use, both technology and user.

- Organization: they allow to reorder the content of a LO according to the pieces that make them up.

- Transformation: they change the units of measurement, of quantification, etc., in the LOs.

Tables 5, 6, 7 and 8 present the use cases of each adaptation rule. The main aspect to remark of these tables is that the precondition is one of the main criteria to determine what possible adaptation can be used in a given context, which can be used by a procedure of selection of adaptation mechanisms.

Table 5. Use Case Description of the Semantic Adaptation

\begin{tabular}{|l|l|}
\hline Use Case & Semantic Adaptation \\
\hline Description & $\begin{array}{l}\text { It allows defining a new semantics of a LO, } \\
\text { incorporating ideas or concepts according to their } \\
\text { contents. }\end{array}$ \\
\hline Precondition & Concepts or ideas required \\
\hline Actors & Adaptive Learning Object \\
\hline Procedure & $\begin{array}{l}\text { Begin } \\
\text { Determine new concepts or ideas or lexicon } \\
\text { Find where to put them into the LO } \\
\text { Incorporate them into the LO } \\
\text { Generate metadata } \\
\text { End }\end{array}$ \\
\hline Fail condition & $\begin{array}{l}\text { - Do not locate the required concepts in data } \\
\text { repositories. } \\
\text { Not having the necessary services for the } \\
\text { extraction of concepts, decomposition and } \\
\text { composition of the LO }\end{array}$ \\
\hline $\begin{array}{l}\text { Success } \\
\text { condition }\end{array}$ & \begin{tabular}{l} 
Construct a LO with new semantics required. \\
\hline
\end{tabular} \\
\hline
\end{tabular}


C. Guevara et al. / Advances in Science, Technology and Engineering Systems Journal Vol. 2, No. 3, 345-355 (2017)

Table 6. Use Case Description of the Presentation Adaptation

\begin{tabular}{|c|c|}
\hline Use Case & Presentation Adaptation \\
\hline Description & $\begin{array}{l}\text { They allow to adapt the presentation of a LO } \\
\text { modifying its format }\end{array}$ \\
\hline Precondition & $\begin{array}{l}\text { - Technological Preferences and limitations } \\
\text { - User Preferences and Limitations } \\
\text { - Conditions of use and desired functionality of the } \\
\text { LO. }\end{array}$ \\
\hline Actors & Learning Object, Context, User \\
\hline Procedure & $\begin{array}{l}\text { Begin } \\
\text { Determine technological preferences and } \\
\text { limitations } \\
\text { Determine user preferences and limitations } \\
\text { Determine conditions of use and functionality of } \\
\text { LO } \\
\text { Customize LO to those preferences and } \\
\text { limitations } \\
\text { Generate metadata } \\
\text { End }\end{array}$ \\
\hline Fail condition & $\begin{array}{l}\text { - Not having the mechanisms to determine } \\
\text { preferences, limitations and desired functionality } \\
\text { of the context } \\
\text { - Not having the necessary services to transform, } \\
\text { customize, decompose or compose a LO }\end{array}$ \\
\hline $\begin{array}{l}\text { Success } \\
\text { condition }\end{array}$ & $\begin{array}{l}\text { - Build a LO with a new presentation, transformed } \\
\text { and/or customized. } \\
\text { - Given some preferences or limitations } \\
\text { recommend formats, customization parameters, } \\
\text { functionality }\end{array}$ \\
\hline
\end{tabular}

Table 7. Use Case Description of the Organizational Adaptation

\begin{tabular}{|c|c|}
\hline Use Case & Organizational Adaptation \\
\hline Description & $\begin{array}{l}\text { It allows reorganizing the contents of a LO by } \\
\text { rearranging its pieces. }\end{array}$ \\
\hline Precondition & $\begin{array}{l}\text { - Pieces or parts desired to organize the content of } \\
\text { the LO } \\
\text { - Concepts or ideas required }\end{array}$ \\
\hline Actors & Adaptive Learning Object \\
\hline Procedure & $\begin{array}{l}\text { Begin } \\
\text { Determine pieces or part of LO. } \\
\text { Determine the reorganization parameters } \\
\text { Rearrange LO } \\
\text { Generate metadata } \\
\text { End }\end{array}$ \\
\hline Fail condition & $\begin{array}{l}\text { Do not locate the required pieces in the LO } \\
\text { repositories. } \\
\text { - Not having the necessary services for the } \\
\text { extraction of pieces, decompose or compose a } \\
\text { LO }\end{array}$ \\
\hline $\begin{array}{l}\text { Success } \\
\text { condition }\end{array}$ & $\begin{array}{l}\text { Build a LO with the new organization of its } \\
\text { content. } \\
\text { Recommend an organization for the LO }\end{array}$ \\
\hline
\end{tabular}

Table 8. Use Case Description of the Transformation

\begin{tabular}{|l|l|}
\hline Use Case & Transformation \\
\hline Description & Modifies certain properties or contents of a LO \\
\hline Precondition & $\begin{array}{l}\text { - Requirement of concept, piece or format. } \\
- \text { Technological or user preferences or limitations } \\
- \text { Usage patterns }\end{array}$ \\
\hline Actors & Adaptive Learning Object \\
\hline
\end{tabular}

\begin{tabular}{|l|l|}
\hline Procedure & $\begin{array}{l}\text { Begin } \\
\text { Summarize the content (concepts, organization) } \\
\text { of a LO. } \\
\text { Transform/Convert values of certain properties } \\
\text { of some units to others (for example, of types } \\
\text { of images, etc.) } \\
\text { Generate metadata } \\
\text { End }\end{array}$ \\
\hline Fail condition & $\begin{array}{l}\text { Not finding the required units in LO } \\
\text { repositories }\end{array}$ \\
\hline $\begin{array}{l}\text { Success } \\
\text { condition }\end{array}$ & $\begin{array}{l}\text { Build a new } \\
\text { transformation of the LO with new features and/or units }\end{array}$ \\
\hline
\end{tabular}

\subsection{Adaptation Metadata}

The LOM standard covers quite well the description of a LO. However, it presents limitations for the adaptation of LOs autonomously. Specifically, the adequacy of a LO is guided by a set of mechanisms, which must be defined in the metadata of the LO. The main mechanisms to be defined are for the adaptation, the conversion, according to the information about the context where will be used the LO. This information is not currently included in the LM standard. For this reason, in this paper, it is proposed to incorporate an extension to the standard (defined as category 10 of the standard), based on the data presented in Table 9.

Table 9. Category 10. Extension proposal for the LOM standard

\begin{tabular}{|c|c|c|c|}
\hline No. & Category & Description & Components \\
\hline 10 & Adaptation & $\begin{array}{l}\text { This category } \\
\text { groups the } \\
\text { necessary } \\
\text { information, to } \\
\text { facilitate the } \\
\text { process of } \\
\text { autonomous } \\
\text { adaptation of a } \\
\text { Learning } \\
\text { Object }\end{array}$ & $\begin{array}{l}\text { 10.1. Adaptation Rules } \\
\text { (Name, Type, Description, } \\
\text { Associated services, } \\
\text { Required inputs, } \\
\text { Procedure, Author, Date of } \\
\text { creation, Date of } \\
\text { modification) } \\
\text { 10.2. Conversion Rules } \\
\text { (Name, Type, Description, } \\
\text { Expected Product, } \\
\text { Associated Services, } \\
\text { Required Inputs, } \\
\text { Procedure, Related Tasks, } \\
\text { Author, Date Created, Date } \\
\text { Modified) } \\
\text { 10.3 Context information } \\
\text { (Knowledge Base, Rules of } \\
\text { Inference, location of the } \\
\text { Knowledge Base) } \\
\text { 10.4 Restrictions } \\
\text { 10.5 Other additional } \\
\text { information }\end{array}$ \\
\hline
\end{tabular}

The proposed category specifies the information used to manage an ALO. The conversion and adaptation rules are methods to be applied to an ALO, which are implemented in some LO management platform. Thus, this category defines the knowledge base that allows the interoperability between ALOs, and their adaptation methods. 


\section{Guevara et al. / Advances in Science, Technology and Engineering Systems Journal Vol. 2, No. 3, 345-355 (2017)}

This category facilitates the search, evaluation, recovery and application of the adaptive methods for an ALO. The ontological model of the Category 10 (OLOMCat10) is presented in Figure 5.

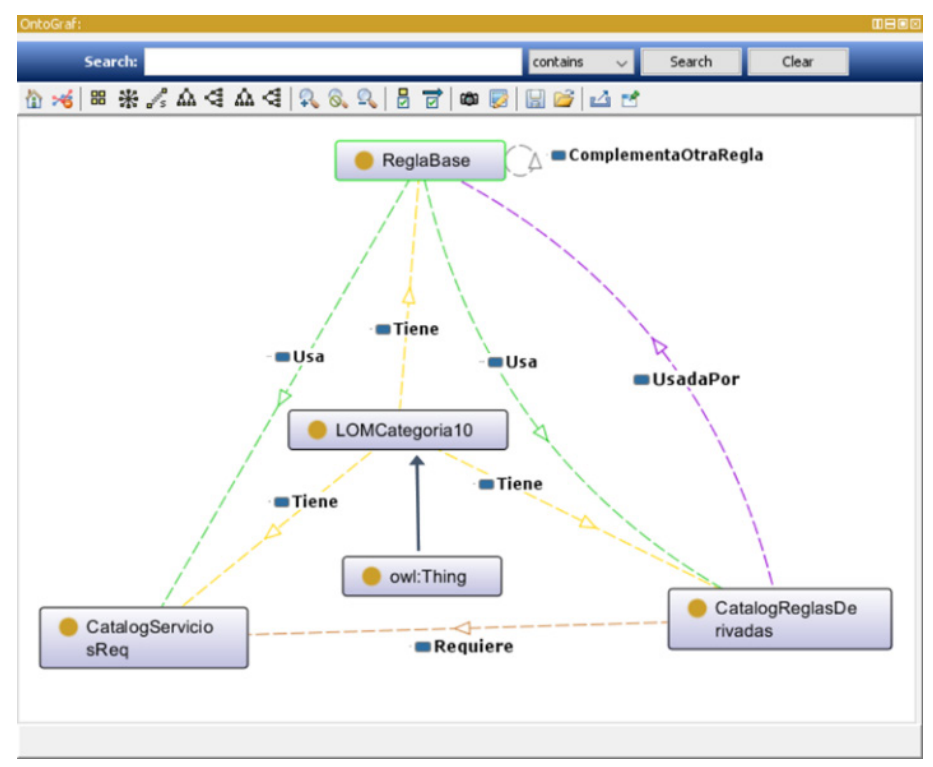

OLOMCat 10 relates Category 10 with 3 major components: a base rule, a rules catalog, and a services catalog. The base rule is the initial rule that triggers the ALO adaptation process. The Rules Catalog describes the set of conversion and adaptive rules. The Services Catalog describes and links a set of mechanisms required during the ALO adaptation process. The purpose of catalogs is ubiquity, making ALO independent of both, the rules of adaptation and the services used to implement them.

\section{MALO instanced by the competencies}

In this section are defined the adequacy of MALO, to consider the competencies during the adaptation process of the LOs.

Considering that the competencies that are applied in the professional field are built on the basis of the training and the professional formation, it is clear to establish a relation between the competencies and the learning results, as expressions of what a person in a learning process knows, understands, and is able to do at the end of an educational process.

As a result, a LO becomes a valid resource within the competence acquisition process, achieving an objective, a result or competence in a specific knowledge [21,25], which is conditioned to the quality of the LO, which involves aspects linked to its structure and granularity, and therefore, its adaptation in all or parts of its components [13].

Adapting a $\mathrm{LO}$ based on competencies requires the adjustment of the LO according to the user's previous competencies and the competencies objective (or learning result), in order that the LO has the sufficient characteristics to cover the competence objectives. In addition, should provide facilities to evaluate the competencies acquired. Thus, within the MALO model, the following aspects must be taken into account:

- Through the conversion rules, the LO must adapt its structure, to add units as required to meet the competence objectives, i.e. the composition rule can add a unit from another LO related to the skill levels of the objective competence.

- By contrast, through the adaptation rules, the LO can update its contextualization. For example, by the organization rule, the contents can be reorganized according to the competence requirements; or through the semantic rule; the LO can be enriched with links to external resources; or also through the transformation rule, the LO can incorporate measures establishing the skill level that a user must achieve after learning the specific knowledge that keeps the object.

- And also through adaptation rules, the LO can propose assessment tools to evaluate the competencies acquired in the learning process

Additionally, the enrichment of a LO with competence metadata can be incorporated into MALO, through the category 9 of the LOM standard (see Table 10), which allows the extension of the specification to a semantic model of competencies that uses a combination of pedagogical strategies and competence taxonomies to classify and evaluate the LO's performance in a learning environment [14].

Table 10. Category 9 of the LOM standard extended to include the competencies

\begin{tabular}{|c|l|l|}
\hline Nro & Category & \multicolumn{1}{c|}{ Explanation } \\
\hline 9 & Classification & $\begin{array}{l}\text { This category describes where this learning } \\
\text { object falls within a particular classification } \\
\text { system. }\end{array}$ \\
\hline 9,1 & Purpose & $\begin{array}{l}\text { The purpose of classifying the LO (discipline, } \\
\text { idea, prerequisite, educational objective, } \\
\text { accessibility, restrictions, educational level, skill } \\
\text { level, security level, competence) }\end{array}$ \\
\hline 9.2 & Taxon path & $\begin{array}{l}\text { A taxonomic path in a specific classification } \\
\text { system. }\end{array}$ \\
\hline 9.3 & Description & $\begin{array}{l}\text { Description of the LO relative to the Purpose, } \\
\text { such as discipline, idea, skill level, educational } \\
\text { objective, competencies, etc. }\end{array}$ \\
\hline 9.4 & Keyword & $\begin{array}{l}\text { Keywords and phrases descriptive of the LO } \\
\text { relative to the Purpose and competencies. }\end{array}$ \\
\hline
\end{tabular}

A hierarchical relationship between the different subcategories of Category 9 of the LOM standard is presented in Figure 6, where the competence (purpose) is defined by a taxonomic classification (taxon path), their description and keywords

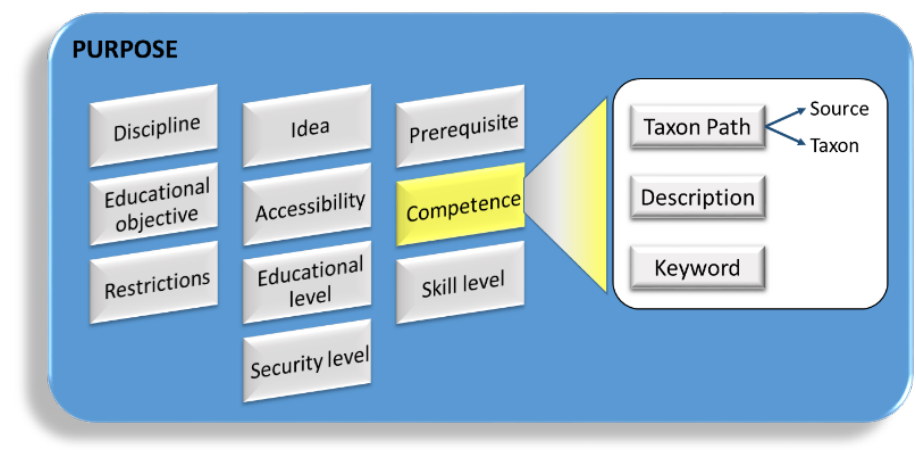

Figure 6. Category 9 of the LOM Standard. Hierarchical description of competence

The use of LO as a resource to generate competencies in an apprentice within a virtual learning environment, requires to adapt the $\mathrm{LO}$ according to the required competencies, learning objective 
and expected results. For this reason, Figure 7 presents a mechanism to instantiate the ALO in order to facilitate this process. For that, it is required:

- Virtual Learning Environment (VLE) provides the necessary environment for the development of the teaching-learning process.

- MALO defines the mechanisms for the LO adaptation
- Adaptation Metadata identifies catalogs of services and rules required to adapt to an ALO.

- Link Services provide ALO connection with VLE, to obtain context information, resources available for learning, as well as access to the Rule and Service catalogs.

- Category 9 of the LOM standard contains the metadata to facilitate the discovery of LO with contents related to the required competencies.

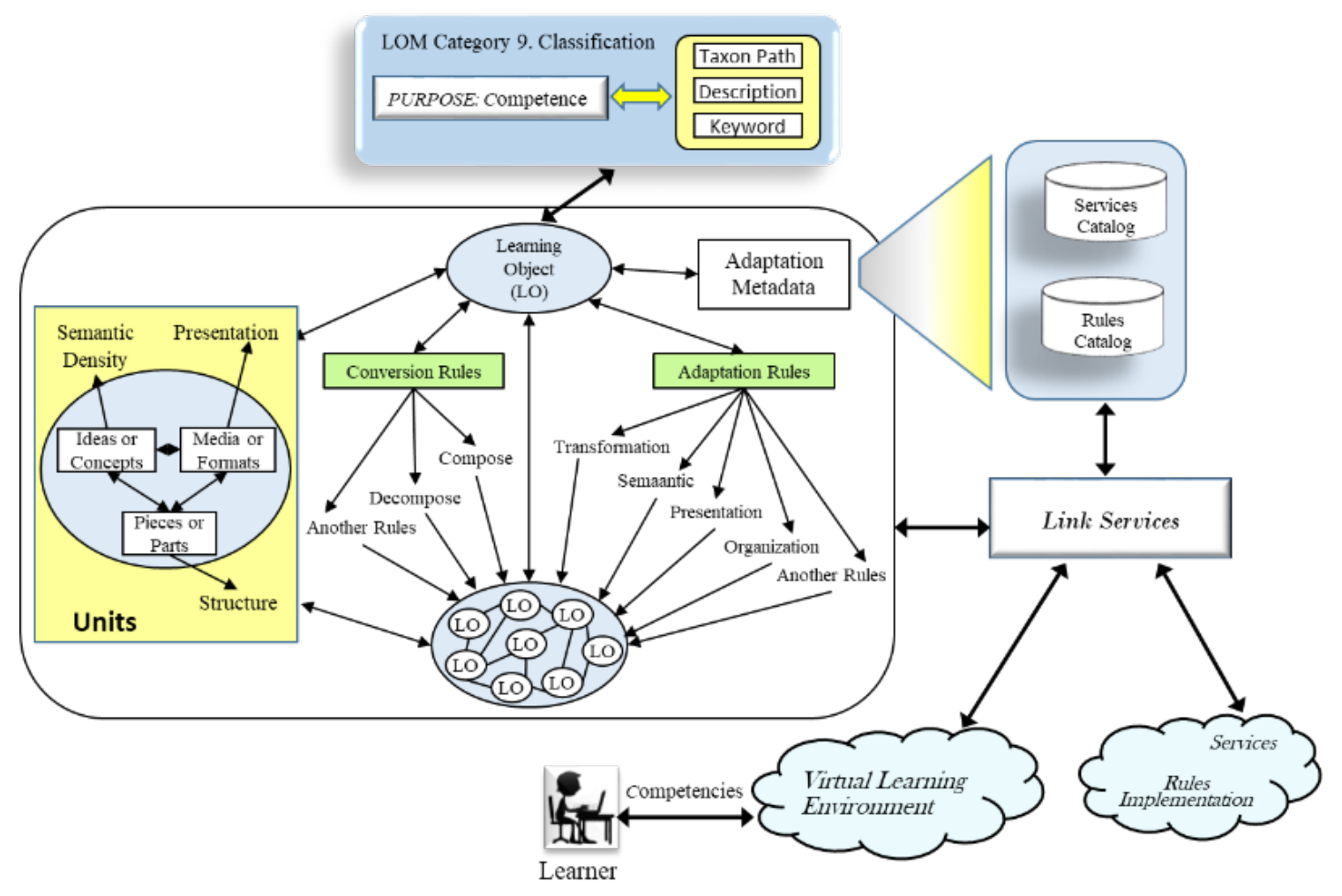

According to Figure 7, the required competencies by the learner are obtained from the VLE. MALO locates resources and LOs, which satisfies the required competencies and LOs. For this, it uses the information of the Category 9 of the LOM standard. MALO provides services with the conversion and adaptation rules defined in the metadata (Category 10), which access the mechanism catalog that allow the adequacy of the ALO according to the requirements. As a result of this process, an ALO is adapted to the competencies.

\section{Description of a Case Study}

Our case study test the capability of reconfiguration of an ALO using MALO, guided by the competencies to be reached in a given course. An application of the competence approach within MALO can be seen in the Table 11, to which the following considerations are carried out:

- It is established as a previous competence of the user: "knowledge of vegetables".

- It is established as objective competence: "Establish the difference between vegetarian dish and any other".
Table 11. Cooking course: Vegetarian dish preparation

\begin{tabular}{|c|c|}
\hline $\begin{array}{l}\text { Course } \\
\text { activities }\end{array}$ & $\begin{array}{l}\text { - Select vegetables and other ingredients (input) } \\
\text { - Prepare mixture (process) }\end{array}$ \\
\hline $\begin{array}{l}\text { Learning } \\
\text { Objects } \\
\text { participants }\end{array}$ & $\begin{array}{l}\text { LO1: Interactive virtual course, where the } \\
\text { apprentice must follow the instructions and } \\
\text { prepare the requested plate } \\
\text { LO2: Digital multimedia content with a catalog of } \\
\text { vegetables, classified by edible and non-edible } \\
\text { vegetables. }\end{array}$ \\
\hline $\begin{array}{l}\text { Content of the } \\
\text { virtual course }\end{array}$ & $\begin{array}{l}\text { The content of the virtual course is composed of } \\
\text { two (02) parts: } \\
\text { Ingredients: in this part the student must } \\
\text { demonstrate his/her knowledge, selecting the } \\
\text { vegetables and other required ingredients. All } \\
\text { ingredients are specified in text form } \\
\text { Preparation: indicated by a video, step by step, } \\
\text { how to prepare the dish. }\end{array}$ \\
\hline Scenario & $\begin{array}{l}\text { - Previous competence: student with extensive } \\
\text { knowledge of vegetables } \\
\text { - Limitations: reading problems. } \\
\text { - Preference: follow hearing instructions }\end{array}$ \\
\hline
\end{tabular}




\begin{tabular}{|l|l|}
\hline & $\begin{array}{c}\text { - Objective competence: LO does not } \\
\text { differentiate between vegetarian and other } \\
\text { dishes }\end{array}$ \\
\hline Classification & $\begin{array}{l}\text { Establish the difference between a vegetarian dish } \\
\text { and any other }\end{array}$ \\
\hline $\begin{array}{l}\text { Previous } \\
\text { Competence }\end{array}$ & Knowledge about vegetables \\
\hline $\begin{array}{l}\text { Objective } \\
\text { Competence }\end{array}$ & $\begin{array}{l}\text { Establish the difference between a vegetarian dish } \\
\text { and others }\end{array}$ \\
\hline Skill Levels & Knowledge $\rightarrow$ Comprehension $\rightarrow$ Application \\
\hline
\end{tabular}

The Table 11 defines the LO to be used, the previous and objective competence, the content of the virtual course to be covered, among other things. Considering that scenario defines that the LO does not meet the objective competence: "Establish the difference between a vegetarian dish and others", then it is necessary to add a LO with knowledge about "Differences between vegetarian and other dishes". For this, in addition to the set of rules explained in section III, should include rules of semantic adaptation, presentation adaptation and transformation, besides to the rule of decomposition and composition. Using MALO, the following procedure will be performed:

1. Application of Presentation Adaptation rules:

1.1. User preferences are determined.

1.2. User Competencies are determined

1.2.1. Previous competence

1.2.2. Objective competence

1.2.3. Skill levels of Objective Competence

1.3. Limitations of the user are determined: reading problems

1.4. Technological preferences are determined: not specified

1.5. Technological limitations are determined: not specified

2. Application of rules of Semantic Adaptation,

2.1. Search for a LO that covers the target competence and user preferences.

2.2. Search for a $\mathrm{LO}$ assessment tool to evaluate the objective competence and its skill levels

2.3. Using Decomposition rules

2.3.1. Units of $\mathrm{LO}$ are retrieved from the source.

3. Application of Transformation rule

3.1. According to the limitations and preferences of the user, 3.1.1. Of the new LO found (LO3), extract audio from video

4. Application of rule of presentation.

4.1. Adjusts the volume of the extracted audio

5. Application of Composition rules,

5.1. The content of LO3 is integrated into the adapted LOs.

6. Application of rules of organization,

6.1. The structure of the adapted $\mathrm{LO}$ is reorganized according to objective competence.

7. Generate the new ALO metadata

7.1. Update the competence metadata in the category 9 of the

LO: purpose, taxon path, description and keyword

8. Product: the $\mathrm{LO}$ was adapted to add the ALO3, which contains the differentiation between a vegetarian dish and others, in audio format, and assessment tools to evaluate the competencies

\section{Comparison of MALO with other Models}

For the comparison of MALO with the previous works described in section I, we consider the most similar that are [4] [6] and [29]. The comparison criteria were based on the characteristics must fulfill an ALO. We have used the next set of criteria: what adapts each one (because in an ALO we can adapt several things: organization, content, presentation, etc.), the type of rules used (that determine the adaptation of the ALO), the architecture of the framework (that determine if it can be improved very easy), the extensibility (very important for its scalability), the flexibility (in order to include new aspects in the adequacy of an ALO), and if it is based on metadata, and particularly, in a standard. The comparison is presented in Table 12.

Table 12. Comparison of MALO with other proposals

\begin{tabular}{|c|c|}
\hline \multicolumn{2}{|c|}{ Criteria for Comparison } \\
\hline \multirow[t]{4}{*}{$\begin{array}{l}\text { Components } \\
\text { to adapt }\end{array}$} & $\begin{array}{l}\text { [5]: content and navigation patterns of a particular } \\
\text { user, according to user preferences }\end{array}$ \\
\hline & [13]: content, navigation and presentation \\
\hline & $\begin{array}{l}\text { [29]: organization of the ALO and assessment } \\
\text { items, }\end{array}$ \\
\hline & $\begin{array}{l}\text { MALO: semantics, presentation and organization } \\
\text { of contents. Possibility of adding other types of } \\
\text { adaptation }\end{array}$ \\
\hline \multirow[t]{4}{*}{ Rules used } & $\begin{array}{l}\text { [5]: propose the use of content adaptation, } \\
\text { navigation and evaluation rules. }\end{array}$ \\
\hline & $\begin{array}{l}\text { [13]: propose rules of navigation, content and } \\
\text { presentation. }\end{array}$ \\
\hline & $\begin{array}{l}\text { [29]: they propose a set of services, but they do not } \\
\text { give a guide about how they must be used }\end{array}$ \\
\hline & $\begin{array}{l}\text { MALO: two categories of rules, adaptation } \\
\text { (semantics, organization, presentation, } \\
\text { transformation) and conversion } \\
\text { (decomposition, composition) are proposed. }\end{array}$ \\
\hline \multirow[t]{3}{*}{ Modularity } & $\begin{array}{l}\text { [5]: is based on rules of adaptation, knowledge of } \\
\text { the domain and the user }\end{array}$ \\
\hline & $\begin{array}{l}\text { [13]: is based on content granularity, adaptive rules } \\
\text { and user domains, context and adaptation }\end{array}$ \\
\hline & $\begin{array}{l}\text { MALO: modular design based on adaptation } \\
\text { components, metadata and internal LO units }\end{array}$ \\
\hline \multirow[t]{4}{*}{ Extensibility } & [5]: They do not propose it \\
\hline & [13]: They do not propose it \\
\hline & [29]: new services can be included \\
\hline & $\begin{array}{l}\text { MALO: It proposes the scalability of the model, } \\
\text { allowing the incorporation of new rules of } \\
\text { adaptation and conversion }\end{array}$ \\
\hline \multirow[t]{4}{*}{ Flexibility } & $\begin{array}{l}\text { [5]: it is fundamentally based on the preferences } \\
\text { and limitations of the user, as well as on their } \\
\text { learning needs. }\end{array}$ \\
\hline & $\begin{array}{l}\text { [13] incorporates preferences and limitations of the } \\
\text { user, as well as learning resources, but does not } \\
\text { consider technological aspects nor patterns of } \\
\text { use }\end{array}$ \\
\hline & $\begin{array}{l}\text { [29] they use the competencies to guide the } \\
\text { adaptation }\end{array}$ \\
\hline & $\begin{array}{l}\text { MALO: possibility to adapt the preferences and } \\
\text { limitations, both user and technologies. }\end{array}$ \\
\hline \multirow{4}{*}{$\begin{array}{l}\text { Adaptation } \\
\text { Metadata }\end{array}$} & [5]: They do not propose \\
\hline & [13]: They do not propose \\
\hline & [29]: they do not propose an adaptive metadata \\
\hline & $\begin{array}{l}\text { MALO: The model works with the IEEE-LOM } \\
\text { standard. It is proposed to incorporate into the } \\
\text { standard an adaptation category, which } \\
\text { describes the new elements used in the } \\
\text { adaptation }\end{array}$ \\
\hline
\end{tabular}




\section{Guevara et al. / Advances in Science, Technology and Engineering Systems Journal Vol. 2, No. 3, 345-355 (2017)}

When comparing the fourth approaches of adaptation of LO, it is observed that there are different criteria to consider. There is also no uniformity in the description of the adaptation metadata, nor in the modularity, extensibility and flexibility that each approach allows.

With respect to MALO, its modular design, extensibility, and the use of standards provide it with greater robustness and flexibility to adjust its strategies and processes. In addition, it is the most complete in terms of what it adapts, the rules it uses, the descriptions it provides in its metadata, among other things.

\section{Conclusions}

The main product of this work is to test the capability of adaptation of MALO using the competencies. Among the main features of the MALO are its modular and independent design based on two categories of rules, adaptation and conversion, which are complemented to facilitate the dynamic adaptation of an ALO. The flexibility and extensibility of its design, allow the incorporation and elimination of rules. In addition, MALO considers the preferences and limitations, both user and technology, as well as the Desired functionality of the LO, and the usage patterns detected in the context.

The competencies determine the skills and knowledge to be obtained in a given course, in this way they give useful information to adapt the $\mathrm{LO}$ to be used during the course. It determines specific conversion and adaptation rules. For example, according to the knowledge to be reached, it can define conversion rules to include new information in a given ALO. Also, according to the skills to be reached, it can define adaptation rules that allow reaching these skills.

There are several future works, in particular, the proposed extension of the LOM (category 10) and the description of the category 9 how a competence metadata, presented in this article, should be detailed. Finally, it is necessary to implement a middleware that provides services to MALO, inspired by works such as [27,28] to manage repositories of ALOs, which autonomously exploit all the knowledge around the MALO, and can adjust an ALO using different frameworks, such as the competencies.

\section{Conflict of Interest}

The authors declare no conflict of interest.

\section{Acknowledgment}

Dr. Aguilar has been partially funded by the "Proyecto Prometeo" of the Ministry of Higher Education, Science, Technology and Innovation (SENESCYT) of the Republic of Ecuador.

\section{References}

[1] D. Wiley, "Connecting learning objects to instructional design theory: A definition, a metaphor, and a taxonomy," 2000. [Online]. Available: http://reusability.org/read/. [Accessed 158 2014].

[2] Q. Jin, Intelligent Learning Systems and Advancements in Computer-Aided Instruction: Emerging Studies, Japan: IGI Global, 2011, p. 378.

[3] M. Rey, R. Díaz, A. Fernández, J. Pazos and M. López, "Objetos adaptativos de aprendizaje para t-learning," IEEE Latin America Transactions, vol. VOL. 5 , no. NO. 6, October 2007, pp. pp. 401-408, 2007.
[4] A. García, L. Marcos and E. García, "An empirical study on m-learning adaptation: Learning performance and learning contexts," Computers \& Education, vol. 82, pp. 450-459, 2015.

[5] J. García, M. Castañón, A. Rodríguez and A. Cristóbal, "Adative Learning Object," in Proceedings of the International Conference on Artificial Intelligence, IC-AI-04, Las Vegas, USA, 2004.

[6] N. Matar, "Multi-Adaptive Learning Objects Repository Structure Towards Unified E-learning," International Arab Journal of e-Technology, vol. 3, no. 3, pp. 129-137, 2014.

[7] S. Hammami and H. Mathkour, "Adaptive e-learning system based on agents and object petri nets (AELS-A/OPN)," Computer Applications in Engineering Education, vol. 23, no. 2, pp. 170-190, 2015.

[8] E. Kurilovasa, S. Kubilinskienea and V. Dagienea, "Web 3.0 - Based personalisation of learning objects in virtual learning environments," Computers in Human Behavior, vol. 30, pp. 654-662, 2014.

[9] D. Mérida, R. Fabregat and S. Baldiris, "Sistemas heterogéneos adaptativos basados en el contexto," RIED. Revista iberoamericana de educación a distancia, vol. Vol 13, no. Nro 2, 2012.

[10] I. Gutierrez, "Usando Objetos de Aprendizaje en Enseñanza Secundaria Obligatoria," EDUTEC-Revista Electrónica de Tecnología Educativa, vol. Nro 27, no. Noviembre 2008, pp. pp. 1-17, 2008.

[11] S. Dietze, S. Sanchez-Alonso and otros, "Interlinking educational resources and the web of data: A survey of challenges and approaches.," Program 47, vol. 1, pp. 60-91, 2013.

[12] J. Aguilar, J. Zechinelli and J. Muñoz, "Hacia la creación y administración de repositorios de objetos de aprendizaje," in Cuarto Encuentro Internacional de Ciencias de la Computación, 2003.

[13] A. Battou, I. Zohr, A. El Mezouary and D. Mammass, "Towards an Adaptive Learning System Based on a New Learning Object Granularity Approach," in (IJACSA) International Journal of Advanced Computer Science and Applications, 2011.

[14] S. Thalmann, "Adaptation criteria for the personalised delivery of learning materials: A multi-stage empirical investigation," Australasian Journal of Educational Technology, vol. 30, no. 1, pp. 45-60, 2014.

[15] C. Guevara and J. Aguilar, "Model of Adaptive Learning Objects for Virtual Environments," in Proceeding of XLII Conferencia Latinoamericana en Informática (CLEI 2016), 2016.

[16] IEEE, "Standard for Learning Object Metadata. Final Draft Standard," 2002. [Online]. Available: http://grouper.ieee.org/groups/ltsc/wg12/files/LOM_1484_12_1_v1_Final_ Draft.pdf. [Accessed 1110 2015].

[17] V. Menéndez, M. Castellanos, A. Zapata and M. Emilio Prieto, "Generación de Objetos de Aprendizaje empleando un enfoque asistido," Pixel-Bit. Revista de Medios y Educación, vol. Nro 38, no. Julio-Diciembre 2010, pp. pp. 141153, 2011.

[18] R. Polsani, "Use and abuse of reusable learning objects," in Journal of Digital Information, 2003.

[19] DCMI, "Dublin Core Metadata Element Set, Version 1.1," 2012. [Online]. Available: http://www.dublincore.org/documents/dces/. [Accessed 2202 2016].

[20] A. J. Romiszowski, "Designing instructional systems: Decision making in course planning and curriculum design," Routledge, 2016.

[21] A. Gonzalez and J. Aguilar, "Semantic Architecture for the Analysis of the Academic and Occupational Profiles Based on Competencies," Contemporary Engineering Sciences, vol. 8, no. 33, p. 1551 - 1563, 2015.

[22] Y. Ossandón Núñez and P. Castillo Ochoa, "Propuesta para el diseño de objetos de aprendizaje," Revista Facultad de Ingeniería-Universidad de Tarapacá , vol. 14, no. 1, pp. 36-48, 2006.

[23] J. Aguilar, I. Bessembel, M. Cerrada, F. Hidrobo and F. Narciso, "Una Metodolog' 1a para el Modelado de Sistemas de Ingeniería Orientado a Agentes," Inteligencia Artificial, vol. 12, no. 38, pp. 39-60, 2008.

[24] J. Aguilar, M. Cerrada and H. F., "A methodology to specify multiagent systems," in Agent and Multi-Agent Systems: Technologies and Applications, Springer, 2007, pp. 02-101. 
[25] D. A. Wiley, Instructional use of learning objects, Agency for instructional technology, 2001.

[26] G. Paquette, "A competency-based ontology for learning design repositories," International Journal of Advanced Computer Science and Applications, vol. 5, no. 1, pp. 55-62, 2014.

[27] J. Vizcarrondo, J. Aguilar, E. Exposito and A. Subias, "ARMISCOM: Autonomic Reflective MIddleware for management Service COMposition," in Proceedings of the 4th Global Information Infrastructure and Networking Symposium, 2012.

[28] V. Bravo, J. Aguilar, F. Rivas and M. Cerrada, "Diseño de un Medio de gestión de Servicios para Sistemas Multiagentes," in Proceeding $X X X$ Conferencia Latinoamericana de Informática, 2004.

[29] A. Nussbaumer, "A competence-based service for supporting self-regulated learning in virtual environments." Journal of Learning Analytics Vol, 2, no.1, pp. 101-133, 2015. 